\title{
Mesh-augmented versus direct abdominal closure in patients undergoing open abdomen treatment
}

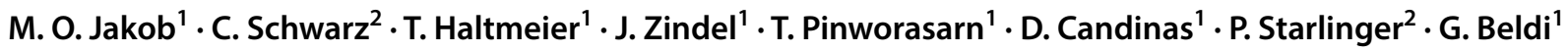

Received: 9 April 2018 / Accepted: 13 July 2018 / Published online: 19 July 2018

(c) The Author(s) 2018

\begin{abstract}
Background Open abdomen (OA) may be required in patients with abdominal trauma, sepsis or compartment syndrome. Vacuum-assisted wound closure and mesh-mediated fascial traction (VAWCM) is a widely used approach for temporary abdominal closure to close the abdominal wall. However, this method is associated with a high incidence of re-operations in short term and late sequelae such as incisional hernia. The current study aims to compare the results of surgical strategies of OA with versus without permanent mesh augmentation.

Methods Patients with OA treatment undergoing vacuum-assisted wound closure and an intraperitoneal onlay mesh (VACIPOM) implantation were compared to VAWCM with direct fascial closure which represents the current standard of care. Outcomes of patients from two tertiary referral centers that performed the different strategies for abdominal closure after OA treatment were compared in univariate and multivariate regression analysis.

Results A total of 139 patients were included in the study. Of these, 50 (36.0\%) patients underwent VAC-IPOM and 89 (64.0\%) patients VAWCM. VAC-IPOM was associated with reduced re-operations (adjusted incidence risk ratio 0.48 per 10-person days; CI 95\% $=0.39-0.58, p<0.001$ ), reduced duration of stay on intensive care unit (ICU) [adjusted hazard ratio (aHR) 0.53; CI 95\% $=0.36-0.79, p=0.002]$ and reduced hospital stay (aHR 0.61; CI 95\% $=0.040-0.94 ; p=0.024$ ). In-hospital mortality [ 22.5 vs $18.0 \%$, risk difference -4.5 ; confidence interval (CI) $95 \%=-18.2$ to $9.3 ; p=0.665$ ] and the incidence of intestinal fistula (18.0 vs $22.0 \%$, risk difference 4.0 ; CI $95 \%=-10.0$ to $18.0 ; p=0.656$ ) did not differ between the two groups. In Kaplan-Meier analysis, hernia-free survival was significantly increased after VAC-IPOM $(p=0.041)$.

Conclusions In patients undergoing OA treatment, intraperitoneal mesh augmentation is associated with a significantly decreased number of re-operations, duration of hospital and ICU stay and incidence of incisional hernias when compared to VAWCM.
\end{abstract}

Keywords Open abdomen · Vacuum-assisted wound closure and mesh-mediated fascial traction • Mesh augmentation . Non-absorbable mesh

Electronic supplementary material The online version of this article (https://doi.org/10.1007/s10029-018-1798-9) contains supplementary material, which is available to authorized users.

G. Beldi

guido.beldi@insel.ch

1 Department of Visceral Surgery and Medicine, University Hospital, Bern, Switzerland

2 Department of Surgery, General Hospital, Medical University of Vienna, Vienna, Austria

\section{Introduction}

Open abdomen $(\mathrm{OA})$ treatment with temporary abdominal closure using negative-pressure wound therapy has become a standard of care in trauma patients undergoing damage control surgery [1]. OA is also increasingly used in nontrauma patients with abdominal sepsis or abdominal compartment syndrome as a life-saving procedure, especially in the growing older population with increased comorbidities and limited physiologic reserve [2].

Temporary abdominal closure needs to ensure the integrity of the abdominal wall and to compartmentalize abdominal contents to avoid treatment-related complications (e.g., intestinal fistula, inability to close the abdominal wall). 
Several methods for temporary abdominal closure have been described of which vacuum-assisted wound closure and mesh-mediated fascial traction (VAWCM) has been reported to be associated with the lowest fistula rate with high rates of fascial closure [3]. However, using the VAWCM technique, multiple surgical revisions are often required for definitive abdominal closure, which may lead to a prolonged ICU and total hospital duration of stay [4]. In addition, these patients exhibit a high rate of incisional hernias of up to $66 \%$ during long-term follow-up potentially because of local fascial traction [5].

Therefore, novel strategies to support the abdominal wall in these patients are required. Synthetic mesh implantation has been shown to effectively support the abdominal wall [6]. However, the use of such meshes in OA may have been limited due to the lack of robust data and due to reports of mesh related complications [7]. We have previously shown that the use of synthetic meshes in patients with peritonitis or fascial dehiscence is an effective approach $[8,9]$. Thus, a therapeutic algorithm that includes mesh-augmented definitive abdominal closure (VAC-IPOM) in this severely ill patient' population has been developed and introduced at the Bern University Hospital in 2005. The aim of this large twocentre study was to compare this VAC-IPOM technique with the current standard of care (VAWCM) in patients undergoing OA treatment.

\section{Materials and methods}

\section{Study design}

All consecutive patients treated for OA between January 2005 and December 2015 from two centers were analyzed. The participating centers were the Department for Visceral Surgery and Medicine, Bern University Hospital, Switzerland (patients with VAC-IPOM) and the Department for Surgery, Medical University of Vienna, General Hospital Vienna, Austria (patients with VAWCM). Patients not using the VAC-IPOM technique at the University Hospital of Bern $(n=22)$ were excluded from the study. Cantonal ethics committee of Bern, Switzerland and the institutional review board of the Medical University of Vienna, Austria have approved this study.

\section{Outcome parameters}

The primary outcome parameter was hernia-free survival. Secondary outcome parameters comprised of general complications such as re-operations, duration of hospital stay, duration of stay on intensive care unit (ICU), mortality and mesh-associated complications such as intestinal fistula and surgical site infection (SSI). SSI infection was defined according to CDC criteria [10]. Intestinal fistula was defined as the persistent leakage of bowel contents within 100 days of the initial OA.

\section{Surgical strategy}

\section{VAWCM group}

OA was covered with abdominal dressings and dynamic tension on fascia was applied to avoid fascial retraction. Dynamic tension on fascia was applied either via vessel loops or temporary inlay meshes as previously described $[11,12]$. The vessel loops were sutured to the anterior sheet of the rectus muscle and constant tension was applied to approximate the fascial edges. In addition, 18 (22.2\%) patients received a temporary large-pore polypropylene inlay mesh. The mesh was sutured to the fascial edges with nonabsorbable sutures and was removed at definitive abdominal closure. The fasciae were closed with absorbable loops.

\section{VAC-IPOM group}

The technique has been previously published [13]. Briefly, patients with OA were treated for one or two cycles with abdominal dressings to stabilize the patients' conditions. After this initial period, intraperitoneal onlay mesh implantation was performed using dual-layered-, large pore, synthetic meshes. Meshes were placed with an overlap of at least $5 \mathrm{~cm}$ on all sides. The meshes were fixed in all corners with a non-absorbable polypropylene suture (Prolene ${ }^{\circledR}$, Ethicon) and the edges were attached to the peritoneum with the same suture. The fascia was partially or completely closed with a PDS running suture (PDS ${ }^{\circledR}$, Ethicon). A vacuum dressing (V.A.C. $\left.{ }^{\circledR}, \mathrm{KCI}\right)$ was then placed on the mesh and continuous suction was applied $(25-75 \mathrm{mmHg}$ suction). Wound treatment included: (1) vacuum dressings until an adequate formation of granulation tissue was achieved and (2) skin re-adaptation with non-resorbable sutures (Dermalon ${ }^{\circledR}$, Covidien).

\section{Statistical analysis}

Data were reported as median and interquartile ranges (IQR), or numbers and percentages, as appropriate. Patients' groups were compared using Fisher's exact test and Mann-Whitney $U$ test for categorical and continuous variables, respectively. Time-to-event outcomes were analysed using the log-rank test. Effects are reported as risk differences or c-statistics with $95 \%$ confidence intervals (CI). The primary endpoint hernia-free survival, was analyzed with Kaplan-Meier curves and a log-rank test for statistical comparison. The effect of mesh treatment on hernia-free survival and secondary outcomes was adjusted in multivariable regression 
analyses. Clinically important and potential confounder variables (age, gender, BMI, emergency primary operation, malignancy, ASA score, immunosuppressive drugs) were tested in univariable models and included in the multivariable model if the $p$ value was below 0.2. Logistic, Cox or Poisson regression were fitted for binary, time-to-event or count outcomes, respectively. Results were reported as odds ratio (OR), hazard ratio (HR) or incidence risk ratio (IRR) with 95\% CI and $p$ values. A two-sided $p$ value of $<0.05$ was considered statistically significant. All statistical tests were performed using SPSS Statistics (Version 17.0.0, SPSS Inc., Chicago, IL).

Table 1 Patients' characteristics

\begin{tabular}{|c|c|c|c|}
\hline & VAWCM $(\mathrm{n}=89)$ & VAC-IPOM $(\mathrm{n}=50)$ & $p$ \\
\hline Age, median in years (IQR) & $55(48-67)$ & $61(55-72)$ & 0.046 \\
\hline Male patients (\%) & $52(58.4 \%)$ & $30(60.0 \%)$ & 1.000 \\
\hline Body mass index in $\mathrm{kg} / \mathrm{m}^{2}$ (IQR) & $24.8(21.0-29.2)$ & $27.3(23.1-35.0)$ & 0.172 \\
\hline Known malignancy (\%) & $36(41.8 \%)$ & $27(54.0 \%)$ & 0.212 \\
\hline Type 2 diabetes (\%) & $15(17.0 \%)$ & $6(12.0 \%)$ & 0.471 \\
\hline Cardiac disease $(\%)$ & $47(52.8 \%)$ & $23(46.0 \%)$ & 0.483 \\
\hline Pulmonary disease (\%) & $16(18.0 \%)$ & $20(40.0 \%)$ & 0.008 \\
\hline Liver disease $(\%)$ & $18(20.2 \%)$ & $14(28.0 \%)$ & 0.303 \\
\hline Kidney disease (\%) & $20(22.5 \%)$ & $9(18.0 \%)$ & 0.665 \\
\hline \multicolumn{4}{|l|}{ Anticoagulation preoperative (\%) } \\
\hline Phenprocoumon & $1(1.2 \%)$ & $5(10.4 \%)$ & 0.024 \\
\hline Platelet aggregation inhibitors & $5(6.0 \%)$ & $4(8.3 \%)$ & 0.723 \\
\hline Dual anticoagulation & $11(13.1 \%)$ & $2(4.2 \%)$ & 0.132 \\
\hline \multicolumn{4}{|l|}{ Immunosuppressors (\%) } \\
\hline Immunosuppressive drugs & $1(1.2 \%)$ & $4(8.2 \%)$ & 0.090 \\
\hline Cortisone & $5(6.2 \%)$ & $2(4.1 \%)$ & \\
\hline Both & $4(4.9 \%)$ & - & \\
\hline \multicolumn{4}{|l|}{ ASA score $(\%)$} \\
\hline 2 & $35(41.7 \%)$ & $8(16.3 \%)$ & $<0.001$ \\
\hline 3 & $43(51.2 \%)$ & $18(36.7 \%)$ & \\
\hline 4 & $3(3.6 \%)$ & $22(44.9 \%)$ & \\
\hline 5 & $3(3.6 \%)$ & $2(4.1 \%)$ & \\
\hline \multicolumn{4}{|l|}{ Type of primary surgery $(\%)$} \\
\hline Hepatobiliary surgery & $4(4.5 \%)$ & $1(2.0 \%)$ & 0.011 \\
\hline Pancreatic surgery & $6(6.7 \%)$ & - & \\
\hline Upper GI surgery & $14(15.7 \%)$ & $6(12.0 \%)$ & \\
\hline Resection of intestine with preserved continuity & $23(25.8 \%)$ & $9(18.0 \%)$ & \\
\hline Resection of intestine without preserved continuity & $19(21.3 \%)$ & $10(20.0 \%)$ & \\
\hline Pancreatic necrosectomy & $3(3.4 \%)$ & - & \\
\hline Multivisceral resections & $4(4.5 \%)$ & $10(20.0 \%)$ & \\
\hline Vascular surgery & $2(2.2 \%)$ & $4(8.0 \%)$ & \\
\hline Other & $14(15.7 \%)$ & $10(20.0 \%)$ & \\
\hline Emergency primary procedure $(\%)$ & $41(46.1 \%)$ & $26(52.0 \%)$ & 0.596 \\
\hline Prior laparotomies, no. (IQR) & $3(1-4)$ & $2(1-3)$ & 0.030 \\
\hline Duration of primary operation in minutes (IQR) & $195(135-318)$ & $240(163-300)$ & 0.416 \\
\hline \multicolumn{4}{|l|}{ Incision at primary procedure $(\%)$} \\
\hline Median laparotomy & $64(75.3 \%)$ & $49(98.0 \%)$ & 0.007 \\
\hline Transverse Laparotomy & $11(12.9 \%)$ & $1(2.0 \%)$ & \\
\hline Combined & $9(10.6 \%)$ & - & \\
\hline Laparoscopy & $1(1.2 \%)$ & - & \\
\hline
\end{tabular}

ASA American Society of Anaesthesiology, IQR interquartile range 


\section{Results}

Meshes used in the VAC-IPOM group include polypropylene-based mesh in 39 (78\%) patients, (Parietene composite ${ }^{\circledR}$, Medtronic, in 34 (87.2\%) patients; Dynamesh ${ }^{\circledR}$, FEG Textiltechnik mbH, in 4 (10.3\%) patients; Vipro ${ }^{\circledR}$, Ethicon, in $1(2.5 \%)$ patient) and polyester-based meshes (Parietex composite ${ }^{\circledR}$, Medtronic) in 11 (22\%) patients. Patients' characteristics are shown in Table 1.

\section{Short-term outcome}

Detailed operative characteristics and postoperative results are shown in Table 2. There was no difference of the intestinal fistula rate and in-hospital mortality between VAWCM and VAC-IPOM. The median number of re-operations after initiation of OA was 5 (IQR 2-13) for VAWCM and 3 (IQR 2-5) for VAC-IPOM (Fig. 1). The incidence of reoperations during hospitalisation per 10-person days after initiation of OA was 1.28 for VAWCM and 0.62 for VACIPOM. Therefore, the adjusted incidence risk ratio for reoperation was 0.48 for VAC-IPOM [ $95 \%$ confidence interval (CI), 0.39-0.58, $p<0.001$ ] (Table 3). Duration of ICU stay was significantly longer for VAWCM compared to VACIPOM [adjusted hazard ratio 0.53 (CI 95\%, 0.36-0.79), $p=0.002$ ] (Fig. 2a). Complete fascial closure was achieved in $66(74.2 \%)$ patients for VAWCM versus $13(26.0 \%)$ patients for VAC-IPOM [risk difference - 48.2 (CI 95\%, -63.3 to -33.0$), p<0.001]$. Duration of hospital stay was significantly longer for VAWCM compared to VAC-IPOM [adjusted hazard ratio 0.61 (CI 95\%, 0.40-0.94), $p=0.024$ ] (Fig. 2b).

\section{Long-term outcome}

Median follow-up was 681 days (311-1091) for VAWCM and $426(178-1058)$ for VAC-IPOM $(p=0.201)$. SSI at last follow-up was found in 3 patients for VAWCM [after a

Table 2 Operative and postoperative results

\begin{tabular}{|c|c|c|c|c|}
\hline & VAWCM $(n=89)$ & VAC-IPOM $(n=50)$ & Effect measure $(95 \% \mathrm{CI})$ & $p$ \\
\hline Occurrence of OA after primary surgery in days (IQR) & $11(4-16)$ & $11(7-17)$ & $0.53(0.43$ to 0.63$)$ & 0.605 \\
\hline Leakage of gastric anastomosis (\%) & $5(5.6 \%)$ & $1(2.0 \%)$ & $-3.6(-9.8$ to 2.5$)$ & 0.419 \\
\hline Leakage of small intestinal anastomosis (\%) & $12(13.5 \%)$ & $9(18.0 \%)$ & $4.5(-8.3$ to 17.3$)$ & 0.471 \\
\hline Leakage of colonic anastomosis $(\%)$ & $3(3.4 \%)$ & $5(10.0 \%)$ & $6.6(-2.5$ to 15.7$)$ & 0.136 \\
\hline Leakage of pancreatic anastomosis (\%) & $1(1.1 \%)$ & $1(2.0 \%)$ & $0.9(-3.6$ to 5.3$)$ & 1.000 \\
\hline Leakage of small intestine and colon (\%) & - & $1(2.0 \%)$ & $2.0(-1.9$ to 5.9$)$ & 0.360 \\
\hline VAC therapy $(\%)$ & $87(97.8 \%)$ & $45(90.0 \%)$ & $-7.8(-16.6$ to 1.1$)$ & 0.098 \\
\hline Duration of redo-surgery in minutes (IQR) & $70(43-110)$ & $111(80-181)$ & $0.72(0.61$ to 0.80$)$ & $<0.001$ \\
\hline Incidence of intestinal fistula until 100 days after OA (\%) & $16(18.0 \%)$ & $11(22.0 \%)$ & $4.0(-10.0$ to 18.0$)$ & 0.656 \\
\hline Occurrence of intestinal fistula before OA (\%) & $7(7.9 \%)$ & $4(8.0 \%)$ & $0.1(-9.2$ to 9.5$)$ & 1.000 \\
\hline Intestinal fistula during OA treatment $(\%)$ & $9(10.1 \%)$ & $7(14.0 \%)$ & $3.9(-7.6$ to 15.4$)$ & 0.582 \\
\hline \multicolumn{5}{|l|}{ Type of intestinal fistula (\%) } \\
\hline Small intestine & $13(14.6 \%)$ & $9(18.0 \%)$ & $3.4(-9.5$ to 16.3$)$ & 0.633 \\
\hline Enteroatmospheric & $3(3.4 \%)$ & $2(4.0 \%)$ & $0.6(-6.0$ to 7.2$)$ & 1.000 \\
\hline In-hospital mortality (\%) & $20(22.5 \%)$ & $9(18.0 \%)$ & $-4.5(-18.2$ to 9.3$)$ & 0.665 \\
\hline \multicolumn{5}{|l|}{ Reason for mortality (\%) } \\
\hline Cardiopulmonary insufficiency & $2(2.2 \%)$ & - & $-2.2(-5.3$ to 0.8$)$ & 1.000 \\
\hline Sepsis/multi-organ failure & $12(13.5 \%)$ & $6(12.0 \%)$ & $-1.5(-13.0$ to 10.0$)$ & 1.000 \\
\hline Underlying disease & $3(3.4 \%)$ & $2(4.0 \%)$ & $0.6(-6.0$ to 7.2$)$ & 0.633 \\
\hline Other ${ }^{\mathrm{A}}$ & $3^{\mathrm{a}}(3.4 \%)$ & $1^{\mathrm{b}}(2.0 \%)$ & $-1.4(-6.7$ to 4.0$)$ & 1.000 \\
\hline Patients requiring intensive care $(\%)$ & $85(95.5 \%)$ & $47(94.0 \%)$ & $-1.5(-9.4$ to 6.4$)$ & 0.702 \\
\hline Days at intensive care unit (IQR) & $20(6-36)$ & $11(6-16)$ & $0.37(0.27$ to 0.46$)$ & 0.002 \\
\hline Termination of OA treatment after initiation in days (IQR) & $28(9-63)$ & $3(0-7)$ & $0.13(0.06$ to 0.19$)$ & $<0.001$ \\
\hline Fascia closed (\%) & $66(74.2 \%)$ & $13(26.0 \%)$ & $-48.2(-63.3$ to -33.0$)$ & $<0.001$ \\
\hline SSI at discharge $(\%)$ & $16(18.0 \%)$ & $27(54.0 \%)$ & $36.0(20.1$ to 52.0$)$ & $<0.001$ \\
\hline Duration of hospital stay in days (IQR) & $66(33-109)$ & $49(34-72)$ & $0.40(0.3$ to 0.49$)$ & 0.007 \\
\hline
\end{tabular}

$I Q R$ interquartile range, $O A$ open abdomen, $S S I$ surgical site infection

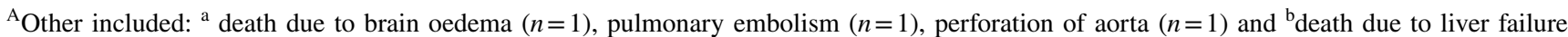
$(n=1)$ 
median of 648 days (151-1207)] and 12 patients for VACIPOM [after a median of 269 days (55-454), $p=0.001$ ]. Hernia-free survival showed a significant curve separation when comparing VAC-IPOM with VAWCM $(p=0.041)$ (Fig. 3).

\section{Mesh-related complications}

SSI at last follow-up did not differ when comparing polypropylene-based meshes with polyester-based meshes $[n=9$ (28.1\%) vs $n=3$ (33.3\%), $p=1.000$ ]. A higher but not significant incidence of SSI was found when fascial closure was not achieved $[n=11(34.4 \%)]$ compared to fascial closure [ $n=1(12.5 \%), p=0.240]$. Partial mesh explantation due to persistent SSI was necessary in $4(9.8 \%)$ patients. There was no difference in partial mesh explantation when comparing polypropylene-based meshes with polyester-based meshes ( $n=3$ polypropylene versus $n=1$ polyester mesh, $p=1.000$ ). We did not find a difference in incidence of intestinal fistula until 100 days after OA ( $n=10$ polypropylene versus $n=1$ polyester mesh, $p=0.416$ ).

\section{Discussion}

The current study shows that VAC-IPOM in patients with OA treatment decrease re-operations, duration of hospital and ICU stay, and the incidence of incisional hernia, when

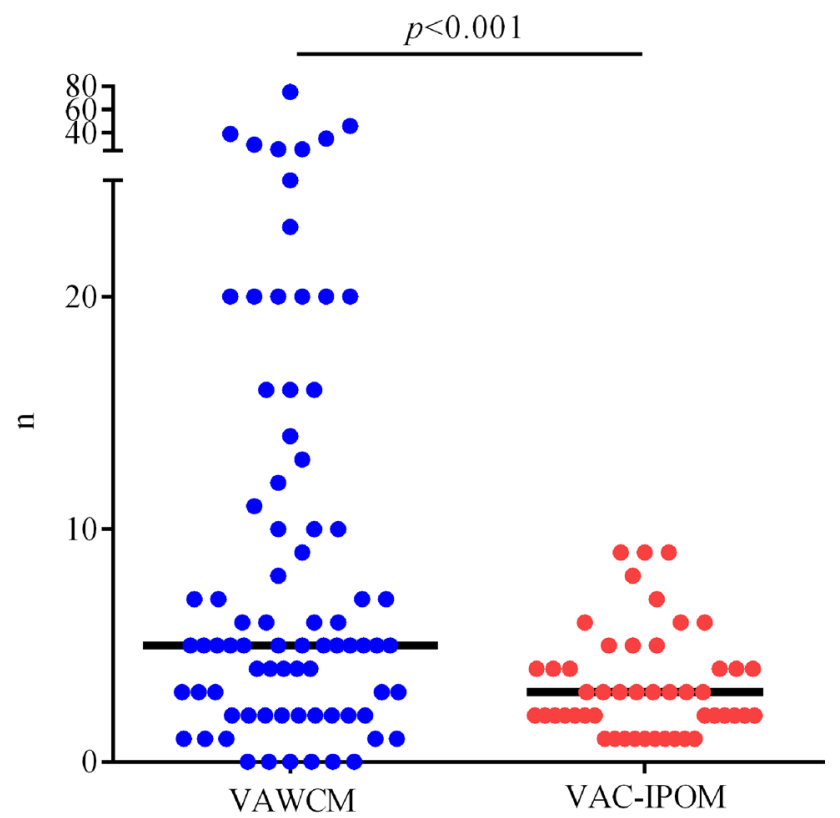

Bars represent median, each dot represents a patient

Fig. 1 Re-operations after initiation of open abdomen until discharge compared with VAWCM, which represents the current standard of care.

OA treatment with temporary abdominal closure should address three main clinical problems: (1) survival of the patient; (2) prevention of short-term complications of the abdominal wall; (3) reduction of long-term complications.

To improve survival and to prevent multi-organ injury in $\mathrm{OA}$, the initial management of abdominal sepsis includes removal of inflammatory ascites $[14,15]$. This is mainly achieved by vacuum therapy, which is offered by both, VACIPOM and VAWCM and thereby potentially explains the comparable in-hospital mortality.

To reduce short-term complications, the integrity of the abdominal wall should be restored as soon as hemodynamic stabilization and removal of septic foci have been achieved. Repetitive abdominal dressings in this setting as required by VAWCM are potentially unnecessary or even harmful leading to a marked increase in duration of stay on ICU.

The fascial closure rate of the current series with VAWCM was similar to a previously published metaanalysis, i.e., $73.1 \%$ [3]. However, the fasciae of $25.8 \%$ of patients using the VAWCM technique were not closed and a planned ventral hernia was the consequence, which could be prevented by the VAC-IPOM technique. In the VAC-IPOM group, fascial closure was not required in the majority of patients because this technique was sufficient to stabilize the abdominal wall and prevented excessive fascial traction. Therefore, high tension to achieve fascial closure can be avoided.

Intestinal fistula is a putative complication in patients with OA and might potentially further complicate the clinical course [16]. The current series supports a growing body of literature showing that the incidence of enterocutaneous fistula in the contaminated abdomen is not different when compared to a cohort without synthetic, intraperitoneal mesh implantation [8, 9, 17-19]. Visceral protection with dual-layered meshes seems to be a key element in prevention of mesh-related intestinal fistula in these patients [20]. Because of this additional barrier function, the VAC-IPOM technique also allows bedside subcutaneous VAC treatment, avoiding unnecessary re-operations.

The frequency of SSI in this population is high and may be complicated by chronic mesh infection [21]. Even though mesh removal is a putative complication for chronic SSI (especially in patients with peritonitis), mesh explantation is rarely necessary [22].

At long-term follow-up, incisional hernia is the most important complication in patients after OA [23, 24]. Even in a series of patients with a very high fascial closure rate of $88 \%$, the rate of incisional hernias remained high with an incidence of at least $28.6 \%$ [25]. These high incidences 
Table 3 Unadjusted and adjusted effect of mesh-augmentation on important outcome variables

\begin{tabular}{|c|c|c|c|c|}
\hline & $\begin{array}{l}\text { Unadjusted } \\
\text { Odds ratio (95\% CI) }\end{array}$ & $p$ & $\begin{array}{l}\text { Adjusted } \\
\text { Odds ratio }(95 \% \mathrm{CI})\end{array}$ & $p$ \\
\hline \multicolumn{5}{|l|}{ In-hospital mortality } \\
\hline VAC-IPOM & $0.76(0.32-1.82)$ & 0.534 & $0.45(0.13-1.61)$ & 0.221 \\
\hline ASA score $>3$ & $2.56(1.02-6.42)$ & 0.045 & $3.92(1.08-14.23)$ & 0.038 \\
\hline Emergency primary procedure & $2.04(0.88-4.71)$ & 0.097 & $3.60(1.13-11.44)$ & 0.030 \\
\hline \multirow[t]{3}{*}{ Immunosuppressive drugs } & $4.72(1.54-14.46)$ & 0.006 & $5.14(1.43-18.44)$ & 0.012 \\
\hline & Unadjusted & $p$ & Adjusted & $p$ \\
\hline & Odds ratio $(95 \% \mathrm{CI})$ & & Odds ratio $(95 \% \mathrm{CI})$ & \\
\hline \multicolumn{5}{|l|}{ Intestinal fistula at 100 days } \\
\hline VAC-IPOM & $1.29(0.54-3.04)$ & 0.566 & $2.06(0.78-5.42)$ & 0.143 \\
\hline ASA score $>3$ & $0.26(0.05-1.02)$ & 0.052 & $0.19(0.04-0.97)$ & 0.045 \\
\hline \multirow[t]{3}{*}{ Emergency primary procedure } & $0.38(0.15-0.94)$ & 0.035 & $0.47(0.18-1.20)$ & 0.114 \\
\hline & Unadjusted & $p$ & Adjusted & $p$ \\
\hline & Hazard ratio $(95 \% \mathrm{CI})$ & & Hazard ratio $(95 \% \mathrm{CI})$ & \\
\hline \multicolumn{5}{|l|}{ Hernia-free survival } \\
\hline VAC-IPOM & $0.30(0.09-1.02)$ & 0.055 & $0.36(0.10-1.27)$ & 0.114 \\
\hline Immunosuppressive drugs & $3.02(0.87-10.5)$ & 0.083 & $2.74(0.78-9.64)$ & 0.116 \\
\hline \multirow[t]{3}{*}{ Age } & $0.97(0.94-1.00)$ & 0.078 & $0.97(0.94-1.01)$ & 0.126 \\
\hline & Unadjusted & $p$ & Adjusted & $p$ \\
\hline & Hazard ratio $(95 \% \mathrm{CI})$ & & Hazard ratio $(95 \% \mathrm{CI})$ & \\
\hline \multicolumn{5}{|c|}{ Duration of stay on Intensive care unit } \\
\hline VAC-IPOM & $0.52(0.36-0.77)$ & $<0.001$ & $0.53(0.36-0.79)$ & 0.002 \\
\hline Emergency primary procedure & $1.26(0.89-1.78)$ & 0.193 & $1.29(0.88-1.89)$ & 0.198 \\
\hline Immunosuppressive drugs & $1.67(0.97-2.90)$ & 0.066 & $1.38(0.79-2.43)$ & 0.257 \\
\hline Age & $1.01(1.00-1.03)$ & 0.034 & $1.01(1.00-1.03)$ & 0.109 \\
\hline \multirow[t]{3}{*}{ Malignancy } & $0.67(0.47-0.95)$ & 0.026 & $0.77(0.53-1.13)$ & 0.189 \\
\hline & Unadjusted & $p$ & Adjusted & $p$ \\
\hline & Hazard ratio $(95 \% \mathrm{CI})$ & & Hazard ratio $(95 \% \mathrm{CI})$ & \\
\hline \multicolumn{5}{|l|}{ Duration of hospital stay } \\
\hline VAC-IPOM & $0.57(0.38-0.87)$ & 0.008 & $0.61(0.40-0.94)$ & 0.024 \\
\hline Age & $1.02(1.00-1.03)$ & 0.029 & $1.01(1.00-1.03)$ & 0.115 \\
\hline \multirow[t]{3}{*}{ Malignancy } & $0.74(0.49-1.01)$ & 0.138 & $0.86(0.58-1.30)$ & 0.484 \\
\hline & Unadjusted & $p$ & Adjusted & $p$ \\
\hline & Incidence risk ratio $(95 \% \mathrm{CI})$ & & Incidence risk ratio (95\% CI) & \\
\hline \multicolumn{5}{|l|}{ Re-operations during OA treatment } \\
\hline VAC-IPOM & $0.49(0.41-0.58)$ & $<0.001$ & $0.48(0.39-0.58)$ & $<0.001$ \\
\hline ASA Score $>3$ & $0.70(0.57-0.85)$ & $<0.001$ & $1.04(0.82-1.32)$ & 0.755 \\
\hline Emergency primary procedure & $0.89(0.78-1.02)$ & 0.090 & $0.89(0.76-1.04)$ & 0.134 \\
\hline Age & $0.99(0.99-0.99)$ & $<0.001$ & $1.00(0.99-1.00)$ & 0.345 \\
\hline Malignancy & $0.69(0.60-0.79)$ & $<0.001$ & $0.75(0.64-0.89)$ & $<0.001$ \\
\hline BMI & $1.00(1.00-1.01)$ & 0.117 & $1.01(1.00-1.01)$ & 0.016 \\
\hline Male gender & $0.81(0.71-0.92)$ & 0.001 & $0.90(0.78-1.04)$ & 0.151 \\
\hline
\end{tabular}

Odds ratios, hazard ratios and incidence risk ratios are shown VAC-IPOM versus VAWCM. Variables with a $p$ value below 0.2 on univariable analysis are displayed

Bold values are considered significant $(p<0.05)$

$95 \%$ CI 95\% confidence interval; ASA American Society of Anaesthesiology 
A Duration of stay on intensive care unit

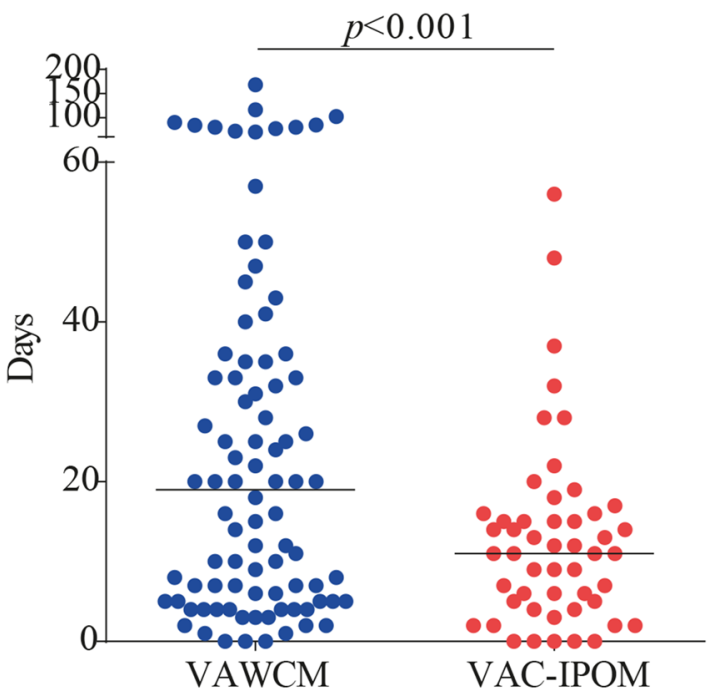

B Duration of hospital stay

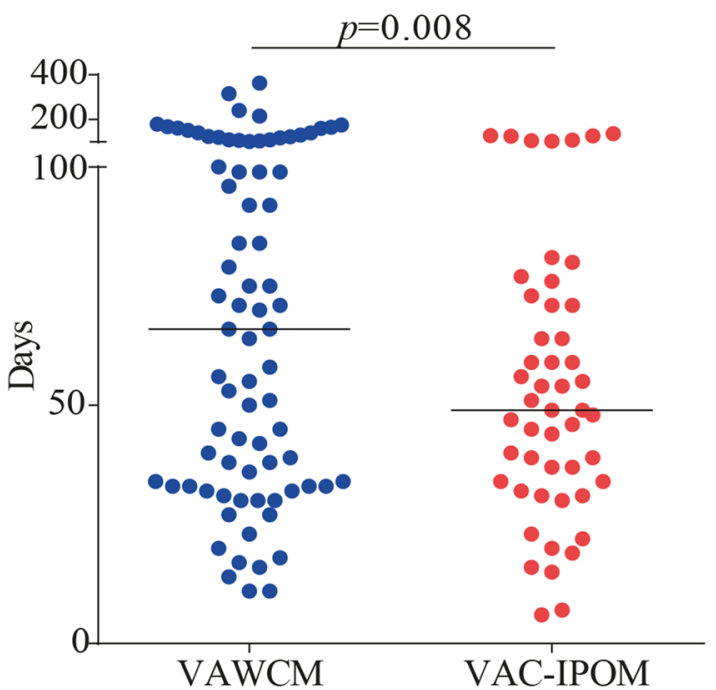

Bars represent median, each dot represents a patient

Fig. 2 a Duration of stay on intensive care unit. b Duration of hospital stay

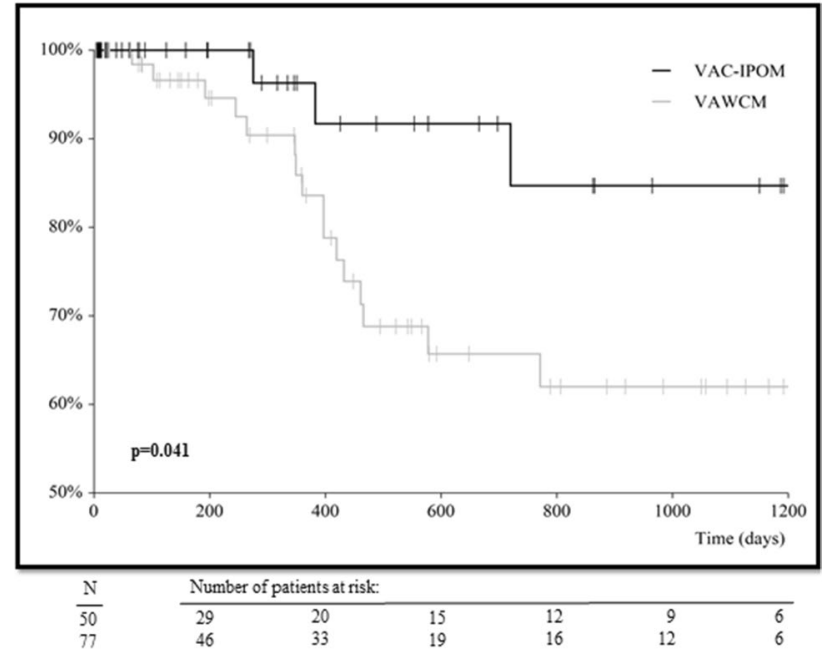

Fig. 3 Hernia-free survival

of incisional hernia and the fact that the collagen structure is comprised in these patients (Fig. SDC 2) indicates the importance of a reinforcement of the abdominal wall. Biologic meshes are an option for the treatment of abdominal wall defects in contaminated fields [26]. However, a recent meta-analysis revealed that biologic meshes were associated with more surgical site complications and hernia recurrence compared to synthetic meshes [27]. Therefore, usage of biologic meshes for such situations should be critically reevaluated [28].
Limitations of this study include its retrospective design and the fact that two different centres were compared with differences in health care. The fact that both hospitals treat a similar number of patients using a comparable surgical spectrum, confounding biases should be reduced. Essentially, prior to data collection, outcome parameters were pre-defined to overcome different definitions. Additionally, the most relevant outcome parameters (Mortality, intestinal fistula, fascial closure, hernia) did not differ compared to other published series [3]. Of note, the current series almost exclusively consists of non-trauma patients.

\section{Conclusion}

In the current study, VAC-IPOM in patients with OA decreased re-operations, duration of hospital and ICU stay, and the incidence of incisional hernia compared to VAWCM. Based on these results, abdominal closure using synthetic mesh-augmentation represents a therapeutic option in patients undergoing OA treatment.

Author contributions MOJ: Study design, data analysis, writing. CHS: Data collection, data interpretation. TH: Statistical analysis, writing. JZ: Histology, writing. TP: Data collection, data interpretation. DC: Study design, critical revision of the manuscript. PS: Study design, data analysis, critical revision of the manuscript. GB: Study design, data analysis, critical revision of the manuscript.

Funding None. 


\section{Compliance with ethical standards}

Conflict of interest MOJ, CHS, TH, JZ, TP, DC, PS and BG declare no conflict of interest.

Ethical approval Cantonal ethics committee of Bern, Switzerland and the institutional review board of the Medical University of Vienna, Austria have approved this study.

Human and animal rights The study including participant has been performed in accordance with the ethical standard of the Declaration of Helsinki and ist later amendments.

Informed consent For this retrospective review, informed consent was not required from both ethical review boards.

Open Access This article is distributed under the terms of the Creative Commons Attribution-NonCommercial 4.0 International License (http://creativecommons.org/licenses/by-nc/4.0/), which permits any noncommercial use, distribution, and reproduction in any medium, provided you give appropriate credit to the original author(s) and the source, provide a link to the Creative Commons license, and indicate if changes were made.

\section{References}

1. Coccolini F, Roberts D, Ansaloni L et al (2018) The open abdomen in trauma and non-trauma patients: WSES position paper. World J Emerg Surg 13:7

2. Weber DG, Bendelli C, Balogh ZJ (2014) Damage control surgery for abdominal emergencies. Br J Surg 101:e109-e118

3. Atema JJ, Gans SL, Boermeester MA (2015) Systematic review and meta-analysis of the open abdomen and temporary abdominal closure techniques in non-trauma patients. World J Surg 39:912-925

4. Willms A, Schaaf S, Schwab R, Richardsen I, Bieler D, Wagner B, Güsgen C (2016) Abdominal wall integrity after open abdomen: long term results of vacuum-assisted wound closure and mesh-mediated fascial traction (VAWCM). Hernia 20:849-858

5. Bjarnason T, Montgomery A, Ekberg O, Acosta S, Svensson M, Wanhainen A, Björck M, Petersson U (2013) One-year follow-up after open abdomen therapy with vacuum-assisted wound closure and mesh-mediated fascial traction. World J Surg 37:2031-2038

6. Jairam AP, Timmermans L, Eker HH et al (2017) Prevention of incisional hernia with prophlyactic onlay and sublay mesh reinforcement versus primary suture only in midline laparotomies (PRIMA): 2-year follow-up of a multicentre, double-blind, randomised controlled trial. Lancet 390:567-576

7. van't Riet M, de Vos van Steenwijk PJ, Bonjer HJ, Steyerberg EW, Jeekel J (2007) Mesh repair for postoperative wound dehiscence in the presence of infection: is absorbable mesh safer than nonabsorbable mesh? Hernia 11:409-413

8. Scholtes M, Kurmann A, Seiler C, Candinas D, Beldi G (2012) Intraperitoneal mesh implantation for fascial dehiscence and open abdomen. World J Surg 36:1557-1561

9. Kurmann A, Barnetta C, Candinas D, Beldi G (2013) Implantation of prohylactic intraperitoneal mesh in patients with peritonitis is safe and feasible. World J Surg 37:1656-1660

10. Horan TC, Gaynes RP, Martone WJ, Jarvis WR, Emori TG (1992) CDC definitions of nosocomial surgical site infections, 1992: a modification of CDC definitions of surgical wound infections. Infect Control Hosp Epidemiol 13:606-608
11. Fortelny RH, Hofmann A, Gruber-Blum S, Petter-Puchner AH, Glaser KS (2014) Delayed closure of open abdomen in septic patients is facilitated by combined negative pressure wound therapy and dynamic fascial suture. Surg Endosc 28:735-740

12. Petersson U, Acosta S, Björck M (2007) Vacuum-assisted wound closure and mesh-mediated fascial traction-a novel technique for late closure of the open abdomen. World J Surg 31:2133-2137

13. Dietz UA, Wichelmann C, Wunder C, Kauczok J, Spor L, Strauss A, Wildenauer R, Jurowich C, Germer CT (2012) Early repair of open abdomen with a tailored two-component mesh and conditioning vacuum packing: a safe alternative to the planned giant ventral hernia. Hernia 16:451-460

14. Carlson GL, Patrick H, Amin AI, McPherson G, MacLennan G, Afolabi E, Mowatt G, Campbell B (2013) Managment of open abdomen: a national study of clinical outcome and safety of negative pressure wound therapy. Ann Surg 257:1154-1159

15. Kubiak BD, Albert SP, Gatto LA, Snyder KP, Maier KG, Vieau CJ, Roy S, Nieman GF (2010) Peritoneal negative pressure therapy prevents multiple organ injury in a chronic porcine sepsis and ischemia/reperfusion model. Shock 34:525-534

16. Connolly PT, Teubner A, Lees NP, Anderson ID, Scott NA, Carlson GLl (2008) Outcome of reconstructive surgery for intestinal fistula in the open abdomen. Ann Surg 247:440-444

17. Birolini C, de Miranda JS, Utiyama EM, Rasslan S (2015) A retrospective review and observations over a 16-year clinical experience on the surgical treatment of chronic mesh infection. What about replacing a synthetic mesh on the infected surgical field? Hernia 19:239-246

18. Chamieh J, Tan WH, Ramirez R, Nohra E, Apakama C, Symons W (2017) Synthetic versus biologic mesh in single-stage repair of complex abdominal wall defects in a contaminated field. Surg Infect 18:112-118

19. Carbonell AM, Criss CN, Cobb WS, Novitsky YW, Rosen MJ1 (2013) Outcomes of synthetic mesh in contaminated ventral hernia repairs. J Am Coll Surg 217:991-998

20. Willms A, Myosoms F, Güsgen C, Schwab R, Lock J, Schaaf S, Germer C, Richardsen I, Dietz U (2017) The open abdomen route by EuraHS: introduction of the data set and initial results of procedures and procedure-related complications. Hernia 21:279-289

21. Petersson P, Montgomery A, Petersson U (2014) Wound dehiscence: outcome comparison for sutured and mesh reconstructed patients. Hernia 18:681-689

22. Argudo N, Pereira JA, Sancho JJ, Membrilla E, Pons MJ, Grande L (2014) Prophylactic synthetic mesh can be safely used to close emergency laparotomy, even in Peritonitis. Surgery 156:1238-1244

23. Patel NY, Cogbill TH, Kallies KJ, Mathiason MA (2011) Temporary abdominal closure: long-term outcomes. J Trauma 70:769

24. Brandl A, Laimer E, Perathoner A, Zitt M, Pratschke J, KafkaRitsch R (2014) Incisional hernia rate after open abdomen treatment with negative pressure and delayed primary fascia closure. Hernia 18:105-111

25. Verdam FJ, Dolmans DE, Loos MJ, Raber MH, de Wit RJ, Charbon JA, Vroemen JP (2011) Delayed primary fascial closure of the septic open abdomen with a dynamic closure system. World J Surg 35:2348-2355

26. Rosen MJ, Krpata DM, Ermelich B, Blatnik JA (2013) A 5-year clinical experience with single-staged repairs of infected and contaminated abdominal wall defects utilizing biologic mesh. Ann Surg 257:991-996

27. Atema JJ, de Vries FE, Boermeester MA (2016) Systematic review and meta-analysis of the repair of potentially contaminated and contaminated abdominal wall defects. Am J Surg 212:982-985.e1

28. Majumder A, Winder JS, Wen Y, Pauli EM, Belyansky I, Novitsky YW (2016) Comparative analysis of biologic versus synthetic mesh outcomes in contaminated hernia repairs. Surgery 160:828-838 